\title{
A novel mutation in the SLC19A2 gene in a Turkish male with thiamine-responsive megaloblastic anemia syndrome
}

\author{
Işık Odaman-Al1, Alper Gezdirici², Melek Yıldız³, Gizem Ersoy¹, Gönül Aydoğan¹, \\ Zafer Şalcıoğlu1 ${ }^{1}$, Tuba Nur Tahtakesen ${ }^{1}$, Hasan Önal ${ }^{4}$, Banu Küçükemre-Aydın ${ }^{3}$ \\ Departments of ${ }^{1}$ Pediatric Hematology and Oncology, ${ }^{2}$ Medical Genetics, ${ }^{3}$ Pediatric Endocrinology and ${ }^{4}$ Pediatric Metabolic \\ Diseases, Kanuni Sultan Suleyman Training and Research Hospital, Istanbul, Turkey. E-mail: dr.odamanal@gmail.com \\ Received: 17th November 2017, Revised: 17th February 2018, Accepted: 10th March 2018
}

SUMMARY: Odaman-Al I, Gezdirici A, Yıldız M, Ersoy G, Aydoğan G, Şalcıoğlu $Z$, Tahtakesen TN, Önal H, Küçükemre-Aydın B. A novel mutation in the SLC19A2 gene in a Turkish male with thiamine-responsive megaloblastic anemia syndrome. Turk J Pediatr 2019; 61: 257-260.

Thiamine-responsive megaloblastic anemia (TRMA) is a very rare syndrome characterized by the triad of early onset megaloblastic anemia, sensorineural deafness and diabetes mellitus. Here we report, a 5-year-old boy who presented with transfusion dependent anemia and diabetes mellitus and was diagnosed with TRMA. Besides reporting a novel mutation of the causative gene SLC19A2, we wanted to emphasize this syndrome in the aspect of coexistence of insulin dependent diabetes, transfusion dependent anemia and thrombocytopenia.

Key words: thiamine-responsive megaloblastic anemia, thrombocytopenia, diabetes mellitus, SLC19A2 mutation.

Thiamine-responsive megaloblastic anemia (TRMA) is a rare autosomal recessive disorder caused by mutations in SLC19A2 gene, encoding a thiamine transporter protein and expressed in a very wide range of tissues including the pancreas, heart, retina, brain and bone marrow. ${ }^{1-5}$ Three cardinal findings of this syndrome are megaloblastic anemia with ringed sideroblasts, diabetes mellitus and sensorineural hearing loss. Additionally, cardiovascular abnormalities and optic atrophy have also been described in some patients. This syndrome was first described by Rogers et al. ${ }^{1}$ in 1969. Pharmacological doses of thiamine (vitamin B1) therapy usually corrects hematological and endocrine function, but results on neurological outcome is not that robust. $2,3,6-8$ TRMA has a variable phenotypic presentation which may cause a significant delay between the onset of symptoms and an accurate diagnosis and treatment.

Here we presented a 5 -year-old boy who was diagnosed with TRMA during evaluations for his transfusion-dependent anemia, thrombocytopenia and insulin dependent diabetes mellitus.
A novel mutation of the SLC19A2 gene was also reported.

\section{Case Report}

The 5-year-old boy was referred to our outpatient clinic for a hematological consultation because of severe anemia. He was born as a second child of healthy third degree consanguineous parents at term with normal birth weight. His physical examination was normal other than pallor and tachycardia. Laboratory analysis revealed anemia with a hemoglobin level of $5.2 \mathrm{~g} / \mathrm{dl}$, hematocrit $16.5 \%$, mean corpuscular volume $85 \mathrm{fl}$, white blood cell count (WBC) $10400 / \mathrm{mm}^{3}$ and platelets (Plt) $203000 / \mathrm{mm}^{3}$ The reticulocyte count was $0.5 \%$. The peripheral blood smear revealed 55\% neutrophil, $40 \%$ lymphocytes, $5 \%$ monocyte, poikilocytosis, anisocytosis, normocytic erythrocytes without atypical cells.

Ferritin level was $255 \mathrm{ng} / \mathrm{ml}$. Folic acid and vitamin B12 levels were all in normal limits. Red blood cell transfusion was done. Hemoglobin electrophoresis, osmotic fragility, pyruvate kinase and G6PDH levels were also 
Table I. Hematological Findings of The Patient During Follow up.

\begin{tabular}{lccccc}
\hline & $\begin{array}{c}\text { Before } \\
\text { thiamine } \\
\text { treatment }\end{array}$ & $\begin{array}{c}\text { 10th day of } \\
\text { treatment }\end{array}$ & $\begin{array}{c}\text { 1st month of } \\
\text { treatment }\end{array}$ & $\begin{array}{c}\text { 3rd month of } \\
\text { treatment }\end{array}$ & $\begin{array}{c}\text { 6th month of } \\
\text { treatment }\end{array}$ \\
\cline { 2 - 6 } Hemoglobin $(\mathrm{g} / \mathrm{dl})$ & 5.2 & 10.3 & 11 & 11.6 & 12 \\
MCV (fl) & 85 & 90 & 87 & 81 & 79 \\
WBC $\left(/ \mathrm{mm}^{3}\right)$ & 10400 & 6980 & 7000 & 5600 & 5900 \\
PLT $\left(/ \mathrm{mm}^{3}\right)$ & 47000 & 128000 & 250000 & 189000 & 240000 \\
\hline
\end{tabular}

MCV: mean corpuscular volume; PLT: platelet; WBC: white blood cell.

in normal range. Direct Coombs test was negative. In the follow up, three months after the first admission, a sudden decrease in hemoglobin level and thrombocytopenia $\left(20000 / \mathrm{mm}^{3}\right)$ was detected. Bone marrow aspiration (BMA) was performed to rule out leukemic infiltration, myelodysplastic syndromes and other pathologies that may cause maturation arrest in granulopoiesis. BMA showed $6 \%$ promyelocytes, $12 \%$ myelocytemetamyelocyte, $39 \%$ neutrophil, normal granulopoiesis, count and morphology of megakaryocytes were normal. Megaloblastic changes and ringed sideroblasts $(>15 \%)$ were observed in erythroid precursors. Monosomy 7 and trisomy 8 FISH analysis obtained for genetic evaluation of myelodysplastic syndromes were also negative. During the follow-up, five months after the first admission, a random laboratory test revealed that his blood glucose level was $365 \mathrm{mg} / \mathrm{dl}$. After endocrinological consultation he was diagnosed with insulin dependent diabetes mellitus and multiple dose insulin therapy was started. Autoantibodies for type 1 diabetes were not detected and with the help of concomitant hematologic abnormalities he was diagnosed with TRMA. His thrombocytopenia and anemia improved very rapidly with oral thiamine nitrat therapy (75 mg/day) (Table I). He was transfusion dependent before thiamine supplementation and red blood cell transfusion was given every two weeks but he did not need any transfusion afterwards. Moreover, insulin doses were reduced after thiamine supplementation. With an informed consent from the parents, the diagnosis of TRMA was confirmed by sequence analysis of the SLC19A2 gene using by next generation sequencing (Mi-seq Illumina) platform which showed a homozygous c. $1265 \mathrm{~T}>\mathrm{C}$ (p. Leu422Pro) mutation (Fig.
1). For investigating other accompanying features of the syndrome; he underwent ophthalmologic, audiologic and cardiologic examination. Unilateral sensorineural hearing loss was detected and the patient was referred to an otolaryngologist for further evaluation. His echocardiography revealed mild pulmonary insufficiency. His ophthalmologic examination was normal other than myopia and astigmatism. At the last follow-up visit he was 5 years and 8 months old and he was on multiple doses of daily insulin therapy $(0.5 \mathrm{U} / \mathrm{kg} /$ day $)$ and his whole blood count values were completely normal. Written consent was receieved from the family.

\section{Discussion}

Thiamine is an essential nutrient for all tissues. Its uptake and transport through the body are relatively complex. At physiological concentrations thiamine is not transported into the cells and requires a high-affinity transporter. ${ }^{9}$ TRMA is caused by mutations in this high affinity thiamine transporter gene (SLC19A2) and the active thiamine uptake is disturbed. Despite the apparent triad of symptoms the diagnosis of TRMA may remain challenging. Up to date, nearly 50 different mutations have been identified in SLC19A2 gene. ${ }^{10}$ We found a homozygous novel mutation, c.1265T >C ( p. Leu422Pro) in our patient. In-silico prediction tools (Mutation taster, PolyPhen-2, Provean and SIFT) classify this mutation as a highly probable pathogenic mutation, as it is located within a highly conserved region.

Thiamine regulates hematopoiesis at the stem-cell level as well as plays a role in DNA metabolism and heme synthesis ${ }^{3}$. The classical hematologic profile in TRMA is megaloblastic anemia which develops early in life, but a 


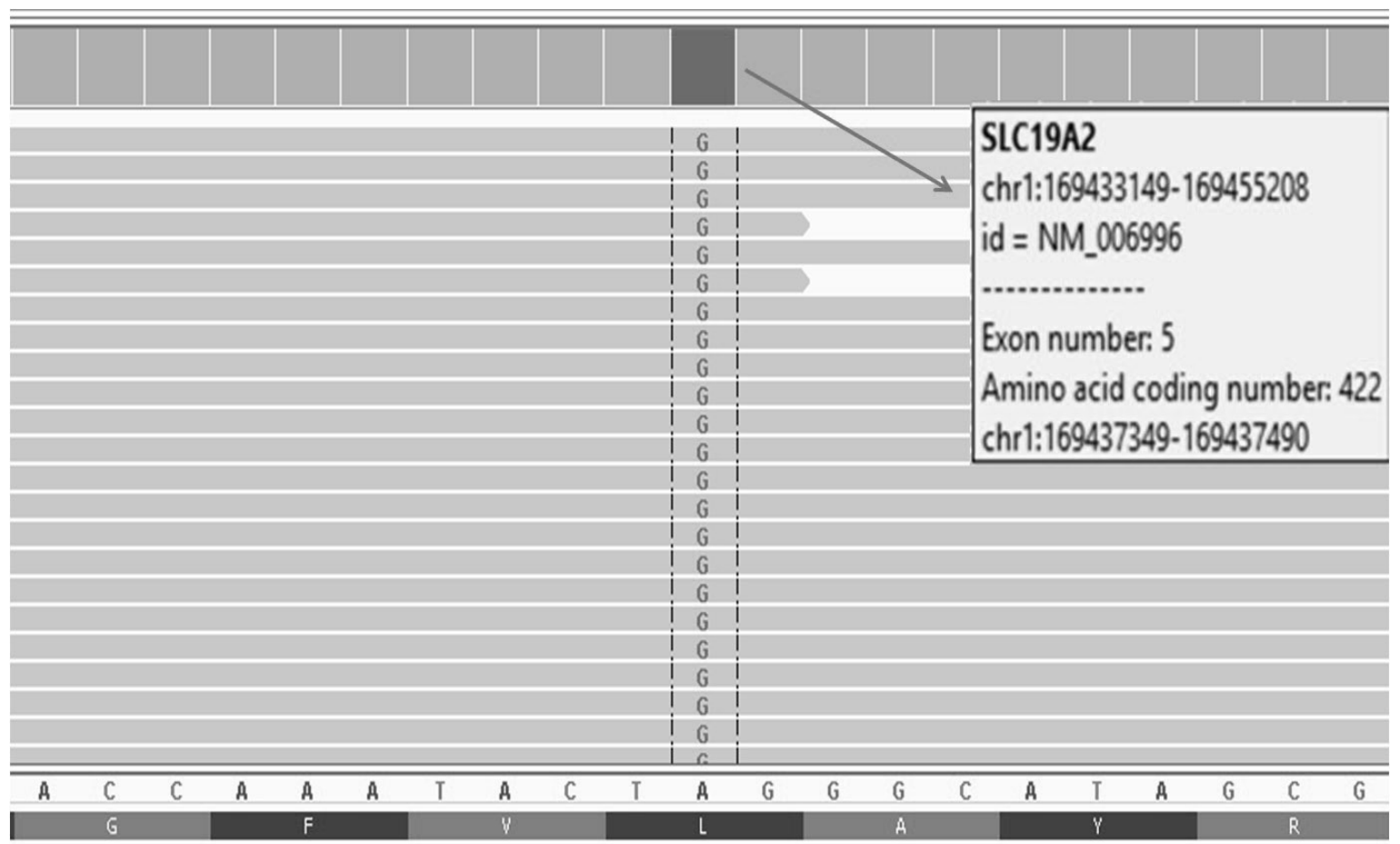

Fig. 1. Sequence analysis of the SLC19A2 gene using by next generation sequencing (Mi-seq Illumina) platform which showed a homozygous c.1265T >C (p. Leu422Pro) mutation.

number of different types of anemia have been reported, such as sideroblastic and aplastic anemia. The bone marrow is characterized by megaloblastic changes and ringed sideroblasts, but also may reveal more diffuse myelodysplasia affecting granulocytic and megakaryocytic differentiation. As a result, thrombocytopenia and pancytopenia have been reported in association with TRMA ${ }^{3,6,8,11}$. Hematological features improve with pharmacological doses of thiamine (25-75 mg/day). However, erythrocytes may remain macrocytic, suggesting a persistent erythropoietic abnormality. ${ }^{12}$ Because the bone marrow is less sensitive to thiamine deprivation, erythroid lineage can repopulate with thiamine treatment. The anemia can recur when thiamine is withdrawn. Furthermore, unresponsiveness to thiamine may develop during treatment. ${ }^{13}$ In our patient, anemia and thrombocytopenia rapidly recovered with thiamine therapy, without side effects.

Pancreas cells require high level of thiamine for its normal endocrine and exocrine function. Insulin secretion is present but defective in TRMA. Non-type I diabetes mellitus may appear anytime from infancy to adolescence in many (though not all) individuals with this disorder.
In some cases, insulin requirement may drop tremendously, even disappear with thiamine therapy. 2,3,6,7,14 However, puberty may deteriorate diabetes control and the reinstitution of insulin therapy would become necessary. In our patient, with the initiation of thiamine treatment insulin requirement diminished, but did not disappear.

Progressive sensorineural hearing loss is generally seen early and may not be prevented by thiamine treatment. ${ }^{8}$ However, there are other studies claiming early treatment may preserve hearing function. ${ }^{15}$ The basis of the sensorineural deafness is not known precisely in TRMA patients; however, animal studies have suggested that selective inner hair cell loss in the cochlea might be the cause of hearing loss. ${ }^{3}$ In our patient hearing loss was also detected and his treatment was pursued by an otolaryngologist.

In conclusion, TRMA is a rare disorder and can be underdiagnosed by pediatric hematologists. The presence of megaloblastic anemia, sensorineural hearing loss and diabetes mellitus, must attract attention to TRMA. Genetic analysis confirms the definitive diagnosis. Early diagnosis and thiamine treatment may 
prevent the complications of hyperglycemia, blood transfusions and sensorineural hearing loss. The aim of this report is to increase the awareness of this syndrome and report a novel mutation.

\section{REFERENCES}

1. Rogers E, Porter SF, Sidbury JR. Thiamine responsive megaloblastic anemia. J Pediatr 1969; 74: 499-504.

2. Yesilkaya E, Bideci A, Temizkan M, et al. A novel mutation in the SLC19A2 gene in a Turkish female with thiamine-responsive megaloblastic anemia syndrome. J Trop Pediatr 2009; 55: 265-267.

3. Ozdemir MA, Akcakus M, Kurtoglu S, Gunes T, Torun YA. TRMA syndrome (thiamine-responsive megaloblastic anemia): A case report and review of the literature. Pediatr Diabetes 2002; 3: 205-209.

4. Fleming JC, Tartaglini E, Steinkamp MP, Schorderet DF, Cohen N, Neufeld EJ. The gene mutated in thiamineresponsive anaemia with diabetes and deafness (TRMA) encodes a functional thiamine transporter. Nat Genet 1999; 22: 305-308.

5. Labay V, Raz T, Baron D, et al. Mutations in SLC19A2 cause thiamine-responsive megaloblastic anaemia associated with diabetes mellitus and deafness. Nat Genet 1999; 22: 300-304.

6. Tahir S, Leijssen LGJ, Sherif M, Pereira C, Morais A, Hussain K. A novel homozygous SLC19A2 mutation in a Portuguese patient with diabetes mellitus and thiamine-responsive megaloblastic anaemia. Int $\mathrm{J}$ Pediatr Endocrinol 2015; 2015: 6.
7. Mozzillo E, Melis D, Falco M, et al. Thiamine responsive megaloblastic anemia: a novel SLC19A2 compound heterozygous mutation in two siblings. Pediatr Diabetes 2013; 14: 384-387.

8. Akın L, Kurtoğlu S, Kendirci M, Akın MA, Karakük $M$. Does early treatment prevent deafness in thiamineresponsive megaloblastic anaemia syndrome? J Clin Res Ped Endocrinol 2011; 3: 36-39.

9. Brown G. Defects of thiamine transport and metabolism J Inherit Metab Dis 2014; 37: 577-585.

10. Stenson PD, Ball EV, Mort M, et al. Human Gene Mutation Database (HGMD): 2003 update. Hum Mutat 2003; 21: 577-581.

11. Bazarbachi A, Muakkit S, Ayas M, et al. Thiamineresponsive myelodysplasia. Br J Haematol 1998; 102: 1098-1100.

12. Neufeld EJ, Mandel H, Raz T, et al. Localization of the gene for thiamine-responsive megaloblastic anemia syndrome, on the long arm of chromosome 1, by homozygosity mapping. Am J Hum Genet 1997; 61: $1335-1341$.

13. Ricketts CJ, Minton JA, Samuel J, et al. Thiamineresponsive megaloblastic anemia syndrome: long-term follow-up and mutation analysis of seven families. Acta Paediatr 2006; 95: 99-104.

14. Yilmaz Y, Aydın BK, Baş F, et al. A thiamine responsive megaloblastic anemia presented with hypertriglyceridemia and auto-immune diabetes. Exp Clin Endocrinol Diabetes Rep 2015; 2: e8-e10.

15. Onal H, Baris S, Ozdil M, et al. Thiamine-responsive megaloblastic anemia: Early diagnosis may be effective in preventing deafness. Turk J Pediatr 2009; 51: 301304. 